\title{
Child pedestrian injury rates: the importance of "exposure to risk" relating to socioeconomic and ethnic differences, in Auckland, New Zealand
}

Ian Roberts, Robyn Norton, Binki Taua

Study objective - To examine how child pedestrian exposure to risk, as measured by the mean number of streets crossed, varies according to indices of material disadvantage and ethnic group.

Design - A questionnaire on pedestrian exposure to risk was distributed to children for completion by parents and return to school. Children from 40 schools were selected using a probability cluster design. Setting - The Auckland region of New Zealand.

Subjects - Questionnaires were distributed to 3388 pupils of whom $2873(85 \%)$ completed and returned the questionnaire. Results - The mean number of streets crossed was $2 \cdot 19$ (95\% confidence interval $1.82,2.56)$ at age 6 years and $2.80(2.42$, $3 \cdot 17)$ at age 9 years. The mean number of streets crossed for boys $(2.57(2.15,2.98))$ was similar to that for girls $(2.38(2 \cdot 05$, $2 \cdot 72)$ ). The mean number of streets crossed by Pacific Island children was $4.87(4 \cdot 01$, $5 \cdot 73)$, more than twice the number crossed by children of predominantly European origin $(1.90(1.65,2 \cdot 15))$. Children from families without a car crossed an average of $5 \cdot 34(4 \cdot 35,6 \cdot 34)$ streets, compared with $2 \cdot 90(2 \cdot 50,3 \cdot 31)$ streets for children from families with one car, and $1.97(1.65,2.29)$ streets for children from families with two or more cars.

Conclusion - There are large differences in pedestrian exposure to risk in relation to ethnic group and levels of car ownership. These differences may explain ethnic and socioeconomic differentials in child pedestrian injury rates.

( $\mathcal{F}$ Epidemiol Community Health 1996;50:162-165)

Injury Prevention

Research Centre,

Department of

Community Health, University of

Auckland, Auckland,

New Zealand

I Roberts

$R$ Norton

$B$ Taua

Correspondence to:

Dr Ian Roberts, Department

of Epidemiology and

Biostatistics, Institute of

Child Health, 30 Guilford

Street, London WC1N

$1 \mathrm{EH}$.

Accepted for publication September 1995 countries and why injury rates change over time. ${ }^{1}$ In New Zealand, nearly all child pedestrian injuries occur on public roads. Children are thus exposed to the risk of pedestrian injury predominantly while crossing roads. Within a population the amount of road crossing by children will vary. Some children make many road crossings each day while others make few or none. Like most population variate values, the number of roads crossed will cluster around a central value, with the probability of finding more extreme values decreasing towards the tails of the distribution. The mean number of roads crossed can be used to locate a population along an axis of pedestrian exposure to risk.

There are steep social class gradients in child pedestrian death rates. In Britain, the pedestrian death rate for children in social class $\mathrm{V}$ is almost five times that of children in social class $\mathrm{I}^{2}{ }^{2}$ Strong socioeconomic gradients also exist for non-fatal child pedestrian injury. ${ }^{3}$ In New Zealand, pedestrian injury rates also vary considerably in relation to ethnic group. The rate for Maori and Pacific Island children is over twice that of children of European origin. These ethnic differences persisted, although somewhat attenuated, after controlling for neighbourhood environmental characteristics. ${ }^{3}$ The socioeconomic and ethnic differences may be due to differences in exposure to risk. A study of the travel patterns of British schoolchildren found that poor children were considerably less likely to travel to school by car and were more likely to walk. ${ }^{4}$

Pedestrian exposure to risk may also explain international differences in death rates. In 1987 and in comparison with Sweden, the child pedestrian death rate in England and Wales was $2 \cdot 3$ times higher, in New Zealand was $2 \cdot 1$ times higher, and in the USA was 1.9 times higher. ${ }^{5}$ Although it has been suggested that Sweden's low injury rates are the result of the greater emphasis on environmental approaches to prevention, without internationally comparable data on pedestrian exposure to risk, it cannot be assumed that road crossing is safer in Sweden.

Answering these questions has implications for prevention. If socioeconomic, ethnic, and international differences in injury rates can be explained in terms of variations in pedestrian exposure to risk, then perhaps greater effort should be directed towards understanding and controlling the determinants of the population mean pedestrian exposure to risk. In this paper 
we report the results of a study of child pedestrian exposure to risk that was conducted in Auckland, New Zealand. The study was conducted as part of "INSECT," (an international study of the exposure of children to traffic). INSECT involves data collection in a number of urban centres internationally, using the same methodology and survey instrument. In this study we use Auckland data to examine how pedestrian exposure to risk varies within a population according to indices of material deprivation and ethnic group.

\section{Methods}

Survey subjects were selected using a probability cluster design. The sampling frame for the primary sampling units (primary schools) was a list of all primary schools, including private and special schools, in the Auckland region of New Zealand. The Auckland region has a predominantly urban population of 936981 of whom approximately 213177 are under 15 years. Forty schools were randomly sampled from the list with a sampling probability in proportion to the number of children on the school roll. Two age groups were selected for study - 6 year olds and 9 year olds. All children in the relevant grade of the selected schools were invited to participate. The survey was conducted in November 1994.

Pedestrian exposure to risk was determined using a questionnaire that was distributed to children in the classroom, to be completed at home with their parents. The questionnaire included questions about each part of the day (before school, going to school, returning from school, and after school) to determine the number and type of streets crossed and whether the child was alone or accompanied. We asked about home and car ownership and about ethnic group. We asked that children complete the questionnaire with their parents in the evening, by systematically reviewing their road crossings for that day. Parents indicated their consent to participate by ticking the relevant box on the questionnaire. The questionnaire had been pilot tested in Seattle, USA and in Melbourne, Australia. Questionnaires were issued on a second occasion if the first was not returned. Response rates were calculated as the proportion of all first issue questionnaires that were completed and returned.

The $S A S$ statistical software package was used to categorise and analyse the data. Because the cluster design can cause an underestimation of the standard error of the outcome variables if simple random sample methods are used, we adjusted the standard errors for design effects using the sample estimate of the intraclass correlation coefficient. ${ }^{6}$ The study was approved by the University of Auckland Human Subjects Ethics Committee.

\section{Results}

Of the 3385 questionnaires that were distributed, 2873 (85\%) were completed and returned. Questionnaires were completed by the parents of 1395 (49\%) boys and $1478(51 \%)$ girls. The study sample comprised 1534 (53\%) 6 year olds and 1339 (47\%) 9 year olds.

Table 1 gives details of the mode of travel to and from school on the day of the survey. For the journey to school at ages 6 and 9 years, most children travelled by car. Almost all of the remaining children walked to school, very few children cycled $(0.6 \%)$ or used public transport $(3 \%)$. Nine year olds were more likely to walk to school $(43 \%)$ than were 6 year olds $(38 \%)$. There was no substantial sex difference in the modes of travel used. The mode of travel was closely associated with car ownership. The proportion of children who walked to and from school increased as the number of family cars decreased. More children walked home from school than walked to school and more children walked home from school unaccompanied by an adult than walked to school. The mode of travel home from school was also closely related to car ownership.

Table 2 gives the mean number of streets crossed in relation to age, sex, ethnic group, and indices of material deprivation (car and home ownership). There were large differences in the number of streets crossed between ethnic groups and in relation to levels of car ownership. Pacific Island children crossed an average of $4.87(4 \cdot 01,5 \cdot 73)$ streets, over two and a half times the number of streets crossed by children of European origin $1.90(1.65,2 \cdot 15)$. Children from families without a car crossed an average of $5.34(4.35,6.34)$ streets compared with $2.90(2 \cdot 50,3 \cdot 31)$ for children from families with one car and $1.97(1.65,2.29)$ for children from families with more than one car.

Table 3 gives the mean number of streets crossed in relation to the level of car ownership, for each ethnic group. The trend of decreasing pedestrian exposure to risk as the number of cars owned increased was evident in all ethnic groups. At each level of car ownership, the number of streets crossed by Pacific Island children was higher than that for Maori and European children.

\section{Discussion}

Pedestrian injury has emerged as the contemporary "disease" of childhood poverty. In Britain, socioeconomic gradients in pedestrian injury mortality are steeper than for any other child health problem. Death rates for children in the lowest class are almost five times those of children in social class one. ${ }^{2}$ In New Zealand there are also strong associations between pedestrian injury risk and ethnic group. These may, however, primarily reflect socioeconomic disadvantage, since the ethnic groups with the highest injury rates are also the most disadvantaged. Understanding the reasons for the socioeconomic and ethnic differentials in injury rates has important implications for prevention. Two hypotheses have been proposed to account for them. The first is that poor children live in more dangerous urban traffic environments, with higher traffic volumes and speeds. ${ }^{7}$ However, a New Zealand case-control study found that the associations between pedestrian injury 
Table 1 Details of journey to school by 2873 pupils aged 6 and 9 years in Auckland in relation to age, sex, and car ownership. Values are percentages

\begin{tabular}{|c|c|c|c|c|c|c|c|}
\hline & \multicolumn{2}{|l|}{ Age } & \multicolumn{2}{|l|}{ Sex } & \multicolumn{3}{|c|}{ No of cars owned } \\
\hline & $\begin{array}{l}6 y \\
(n=1534)\end{array}$ & $\begin{array}{l}9 y \\
(n=1339)\end{array}$ & $\begin{array}{l}\text { Boys } \\
(n=1395)\end{array}$ & $\begin{array}{l}\text { Girls } \\
(n=1478)\end{array}$ & $\begin{array}{l}0 \\
(n=140)\end{array}$ & $\begin{array}{l}1 \\
(n=1045)\end{array}$ & $\begin{array}{l}>=2 \\
(n=1688)\end{array}$ \\
\hline \multicolumn{8}{|l|}{ fourney to school } \\
\hline Walked & $38 \cdot 0$ & $43 \cdot 4$ & $40 \cdot 0$ & $41 \cdot 0$ & $82 \cdot 8$ & $50 \cdot 7$ & $30 \cdot 6$ \\
\hline Car & $59 \cdot 3$ & 52.7 & $56 \cdot 3$ & $56 \cdot 2$ & $16 \cdot 4$ & $47 \cdot 0$ & $65 \cdot 3$ \\
\hline Public transport & 3.0 & $3 \cdot 4$ & $3 \cdot 3$ & $3 \cdot 2$ & $1 \cdot 4$ & 1.8 & $4 \cdot 3$ \\
\hline Bicycle & $0 \cdot 3$ & $1 \cdot 0$ & $1 \cdot 0$ & 0.3 & 0.0 & 1.0 & 0.5 \\
\hline \multicolumn{8}{|l|}{ Accompanied by (walkers only): } \\
\hline Alone & $12 \cdot 0$ & $24 \cdot 1$ & $22 \cdot 0$ & $14 \cdot 4$ & $12 \cdot 1$ & $17 \cdot 9$ & $19 \cdot 5$ \\
\hline Child same age or younger & $48 \cdot 2$ & $59 \cdot 4$ & 51.9 & 55.5 & $50 \cdot 0$ & $57 \cdot 9$ & $50 \cdot 4$ \\
\hline Older child & $4 \cdot 6$ & $2 \cdot 8$ & $3 \cdot 4$ & $4 \cdot 0$ & $6 \cdot 0$ & $3 \cdot 8$ & $3 \cdot 1$ \\
\hline \multirow{2}{*}{\multicolumn{8}{|c|}{ Fourney from school }} \\
\hline & & & & & & & \\
\hline Walked & $46 \cdot 9$ & $57 \cdot 5$ & $51 \cdot 0$ & $52 \cdot 7$ & $86 \cdot 4$ & $61 \cdot 2$ & $43 \cdot 2$ \\
\hline Car & $48 \cdot 9$ & $37 \cdot 3$ & 43.8 & $43 \cdot 2$ & $12 \cdot 1$ & $35 \cdot 4$ & $51 \cdot 1$ \\
\hline Public transport & $3 \cdot 8$ & $4 \cdot 2$ & $4 \cdot 2$ & $3 . \overline{9}$ & $1 \cdot 4$ & $2 \cdot 3$ & $5 \cdot 3$ \\
\hline Bicycle & 0.3 & 1.0 & $1 \cdot 1$ & $0 \cdot 2$ & 0.0 & $1 \cdot 1$ & 0.4 \\
\hline \multicolumn{8}{|c|}{ Accompanied by (walkers only): } \\
\hline Alone & $12 \cdot 9$ & $20 \cdot 4$ & $18 \cdot 1$ & $15 \cdot 6$ & $8 \cdot 3$ & $17 \cdot 7$ & $17 \cdot 5$ \\
\hline Child same age or younger & $57 \cdot 1$ & $67 \cdot 4$ & $63 \cdot 2$ & $61 \cdot 7$ & $57 \cdot 9$ & $62 \cdot 5$ & $63 \cdot 0$ \\
\hline Older child & $1 \cdot 8$ & $1 \cdot 8$ & 1.5 & $2 \cdot 1$ & $5 \cdot 0$ & 1.6 & 1.5 \\
\hline Adult & $28 \cdot 2$ & $10 \cdot 4$ & $17 \cdot 2$ & $20 \cdot 7$ & 28.9 & $18 \cdot 3$ & $18 \cdot 0$ \\
\hline
\end{tabular}

and indices of material disadvantage and ethnic group persisted, albeit slightly attenuated, after controlling for traffic volume and speed. ${ }^{3}$ In this study, it was observed that the risk of injury for children from families without a car was twice that of children from families with a car. This observation suggested a second hypothesis: that poor children cross more roads than more affluent children and are thus exposed to greater risk. The present study aimed to test the latter hypothesis by examining the extent to which child pedestrian exposure to risk varies within a population according to indices of material disadvantage and ethnic group.

The results indicate that there are considerable differences in pedestrian exposure to risk according to car ownership and ethnic group. These differences are large enough to explain the observed ethnic and socioeconomic differentials in pedestrian injury risk. For car ownership, the ratio of the number of roads crossed by children from families without and with a car $(2 \cdot 3)$ is almost identical to the odds ratio associated with lack of access to a car that was observed in a case-control study in the same population (OR $=2 \cdot 1 \quad 95 \%$ confidence interval $(95 \% \mathrm{CI}) 1.36,3 \cdot 10)$. Because the case-control study included children aged 0-14 years and children who were injured at times other than schooldays, direct comparison of these data sets is not entirely appropriate.

Table 2 Mean number of streets crossed and 95\% confidence intervals

\begin{tabular}{|c|c|c|c|}
\hline Variable & Local streets & Main streets & Total streets \\
\hline \multicolumn{4}{|l|}{ Age: } \\
\hline $6 y$ & $1.77(1.52,2.03)$ & $0.42(0.25,0.58)$ & $2 \cdot 19(1 \cdot 82,2 \cdot 56)$ \\
\hline $9 \mathrm{y}$ & $2.30(2.03,2.58)$ & $0.49(0.34,0.65)$ & $2 \cdot 80(2 \cdot 42,3 \cdot 17)$ \\
\hline \multicolumn{4}{|l|}{ Sex: } \\
\hline Male & $2.08(1.80,2.36)$ & $0.49(0.31,0.67)$ & $2.57(2.15,2.98)$ \\
\hline Female & $1.97(1.71,2.22)$ & $0.42(0.27,0.56)$ & $2 \cdot 38(2 \cdot 05,2 \cdot 72)$ \\
\hline \multicolumn{4}{|l|}{ Ethnic group: } \\
\hline Maori & $2 \cdot 61(2 \cdot 26,2 \cdot 95)$ & $0.58(0.39,0.77)$ & $3.19(2.75,3.63)$ \\
\hline Pacific Island & $3.66(3.07,4.24)$ & $1.21(0.81,1.61)$ & $4 \cdot 87(4 \cdot 01,5 \cdot 73)$ \\
\hline Other & $1.62(1.42,1.81)$ & $0.29(0.18,0.39)$ & $1.90(1.65,2 \cdot 15)$ \\
\hline \multicolumn{4}{|l|}{ No of cars owned: } \\
\hline 0 & $3.73(3.03,4.43)$ & $1 \cdot 61(1 \cdot 08,2 \cdot 15)$ & $5 \cdot 34(4 \cdot 35,6 \cdot 34)$ \\
\hline 1 & $2.37(2.07,2.68)$ & $0.53(0.36,0.70)$ & $2 \cdot 90(2 \cdot 50,3 \cdot 31)$ \\
\hline$>=2$ & $1.66(1.43,1.89)$ & $0.31(0.17,0.45)$ & $1.97(1.65,2.29)$ \\
\hline \multicolumn{4}{|l|}{ Home owner: } \\
\hline No & $2 \cdot 44(2 \cdot 08,2 \cdot 80)$ & $0.84(0.58,1.09)$ & $3.28(2.74,3.82)$ \\
\hline Yes & $1.90(1.66,2.15)$ & $0.34(0.21,0.47)$ & $2.25(1.92,2.57)$ \\
\hline
\end{tabular}

Nevertheless the results support the contention that pedestrian exposure to risk underlies the association with car access. Moreover, the results show a "dose response relation," with pedestrian exposure increasing as car ownership decreases. This observation underscores the unequal societal distribution of the health advantages and disadvantages of car travel. Children from families without a car receive none of the benefits of car travel but a greater share of the risks. An analogy might be drawn with secondary smoking. Cigarette consumption by smokers adversely effects the health of nonsmokers. In the context of pedestrian injury, the volume of road traffic is one of the strongest risk factors for injury. Thus, car travel by more affluent families increases the injury risk for children from families without a car.

The results also indicate that ethnic differences in pedestrian exposure are not entirely attributable to differences in car ownership. Pacific Island children from families who do not own a car cross substantially more roads than do European children from families with no car. Pacific Island children are very much over-represented among the most disadvantaged groups in Auckland so that it is possible that there may be some residual confounding by factors related to socioeconomic deprivation. For example, European children in non-car owning families may have more access to car travel with friends and relatives than would Pacific Island children. Another possible explanation is that Pacific Island children may live further away from schools, because housing situated close to schools may be more expensive. Alternatively the greater pedestrian exposure of Pacific Island children may reflect cultural differences in parental expectations.

Very few children used public transport for the journey to and from school. Only 3\% of the Auckland 9 year olds travelled to school by public transport. A British survey of the travel patterns of Newcastle school children found that $34 \%$ of 11 year olds travelled to school by public transport. ${ }^{4}$ The results are not directly comparable because of the difference in the 
Table 3 Mean number of streets crossed (95\% confidence interval) in relation to car ownership and ethnic group

\begin{tabular}{llll}
\hline Variable & Pacific Island & Maori & Other \\
\hline No car & $7 \cdot 34(5 \cdot 35$, & $4 \cdot 10(3 \cdot 10$, & $4 \cdot 20(3 \cdot 17$, \\
& $9 \cdot 33)$ & $5 \cdot 09)$ & $5 \cdot 24)$ \\
One car & $4 \cdot 59(3 \cdot 27$, & $3 \cdot 42(2 \cdot 86$, & $2 \cdot 18(1 \cdot 86$, \\
& $5 \cdot 46)$ & $3 \cdot 98)$ & $2 \cdot 49)$ \\
Two cars (or & $4 \cdot 23(2 \cdot 78$, & $2 \cdot 69(2 \cdot 14$, & $1 \cdot 71(1 \cdot 47$, \\
more) & $5 \cdot 67)$ & $3 \cdot 24)$ & $1 \cdot 94)$ \\
\hline
\end{tabular}

age of the children surveyed. Nevertheless, greater use of public transport by children would have the potential to reduce exposure to risk by those children who would otherwise walk to and from school.

Some potential limitations of this study may have a bearing on the validity of the results. First, although the response rate was high $(85 \%)$, it is possible that disadvantaged children with high pedestrian exposure would be over-represented among the non-responders, so that the estimates of pedestrian exposure may be underestimates. Nevertheless, this would not constitute a plausible explanation for the observed patterns of pedestrian exposure by ethnic group and car ownership. Second, pedestrian exposure was determined by self report so that the validity of the data are open to question. The validity of interview reported pedestrian activity was studied by Routledge who observed a child pedestrian's activity one day and interviewed the same child the following day. ${ }^{8}$ Observers recorded all road crossings and road entries. The results revealed that pedestrian exposure was slightly under reported, $86 \%$ of the number of roads observed to be crossed were reported. However, under reporting in this situation is likely to be due to children forgetting road crossings and is likely to be similar for different groups of children. Moreover, in our study we attempted to minimise under reporting by asking children to complete the questionnaire with their parents in the evening, by systematically reviewing their road crossings for that day.

In summary, these results show that car ownership is a key determinant of child pedestrian exposure to risk. Since car ownership is intimately related to socioeconomic circumstances, this observation provides the most compelling explanation for socioeconomic gradients in pedestrian injury rates. Because car travel contributes to traffic volume it increases the pedestrian injury risk for those without access to a car. In this way, child pedestrian injury might be viewed as a direct consequence of an unequal societal distribution of wealth. Indeed, it is interesting to speculate whether the extraordinarly low child pedestrian injury rate in Sweden is related to its more equitable distribution of income. These results have important implications for public health. They suggest that one approach to the prevention of childhood traffic injury is that of tackling socioeconomic inequality itself. The low use of public transport by children points to another preventive strategy. Strengthening the public provision of alternatives to car travel and encouraging the use of public transport by children might reduce traffic volume and at the same time reduce the exposure to risk of children who are denied the option of car travel. Finally, the wider implementation of traffic calming measures and the provision of safe cycle tracks would reduce the injury risk for children who walk or cycle to school. This strategy might also persuade car owning parents to allow their children to enjoy the health benefits of walking and cycling.

The study was funded by Accident Compensation Corporation of New Zealand.

1 Roberts I. Injuries to child pedestrians. BMF 1995;310:413-4

2 Woodroffe C, Glickman M, Barker M, Power C. Children teenagers and health: the key data. Buckingham: Open University Press, 1993

3 Roberts I, Norton R, Jackson R, Dunn R, Hassall I. Effect of environmental factors on risk of injury of child pedestrians by motor vehicles: a case-control study. $B M \mathcal{F} 1995$ 310:91-4

4 Towner EML, Jarvis SN, Walsh SSM, Aynsley-Green A Measuring exposure to injury risk in schoolchildren aged 11-14. BMF 1994;308:449-52.

5 Roberts I. International trends in pedestrian injury mortality. Arch Dis Chld 1993;68:190-2.

6 Kish L. Survey sampling. New York: John Wiley \& Sons, 1965.

7 Rivara FP. Child pedestrian injuries in the United States. $\mathrm{Am}$ f Dis Child 1990;144:692-6.

8 Routledge DA, Repetto-Wright R, Howarth CI. A comparison of interviews and observation to obtain measures of children's exposure to risk as pedestrians. Ergonomics 1974;17:623-38. 